\title{
ESTADO E INTEGRACIÓN: MOVIMIENTOS DE LARGA DURACIÓN, NOCIÓN DE ESTADO Y PREGUNTAS DE INVEST IGACIÓN
}

\author{
Patricio Valdivieso \\ Instituto de Ciencia Politica \\ Pontificia Universidad Católica de Chile
}

Actualmente se reconoce la necesidad de avanzar en la comprensión de las tareas de futuro que debemos emprender en Chile, y ello será posible a partir del entendimiento de las megatendencias que afectan la sociedad chilena y que debieran dar la orientación, a las posibilidades y los límites de la acción colectiva como nación.

En este estudio se identifican y precisan tres de los movimientos de larga duración o megatendencias que están afectando al país, se exponen algunas indagaciones sobre la noción de estado que demanda nuestro tiempo histórico, sobre principios normativos orientadores, y finalmente quedan formuladas algunas preguntas de investigación. En calidad de apéndice, se incluye una selección de trabajos académicos que complementan la perspectiva desarrollada en el estudio.

\section{MOVIMIENTOS DE LARGA DURACIÓN}

El debate nacional en torno a los desafíos del Estado chileno debe considerar las posibilidades y límites de su acción en la etapa de transición hacia el nuevo milenio. De los procesos o tendencias nacionales e internacionales que nos están afectando como sociedad en la actualidad, y que por lo tanto condicionan nuestras acciones, hay por lo menos tres que demandan nuestro reconocimiento: la globalización, el pluralismo, y la democracia. Entonces, cabe partir por precisar el sentido y el alcance de estos conceptos.

\section{Globalización}

La creciente extensión espacial de las relaciones económicas, culturales y políticas, y la progresiva interdependencia de actores y problemas en el mundo, dan lugar a la percepción de un desarrollo global en el planeta. La globalización es resultado de progresos tecnológicos, de los medios de transporte y de las comunicaciones. Pero también van generándose desafíos globales que demandan acciones colectivas favorables a la globalización, tales como los problemas medioambientales y de seguridad internacional, entre otros.

Las fronteras políticas, económicas y culturales de los estados nacionales parecen estar siendo afectadas por el desarrollo global, en mayor medida que en otros tiempos. Diversos actores intergubernamentales y no gubernamentales tienen consecuencias en el sistema internacional. En las relaciones económicas mundiales, se observa una creciente internacionalización de los merca- 
dos de bienes, de servicios y financieros: Los mercados financieros tienden a operar más 0 menos coordinadamente en todas partes del mundo y aumenta la interdependencia financiera. Las inversiones extranjeras pasan a tener un papel fundamental en las economías nacionales, y los empresarios producen crecientemente para mercados regionales y/ o mundiales. Las distancias pierden significado gracias a los avances tecnológicos en transportes y comunicaciones. Todas estas tendencias se ven favorecidas por la creciente liberalización del orden económico internacional, y también por la acelerada integración de nuevos actores en el comercio mundial (China e India, por ejemplo).

Desde el punto de vista del bienestar económico y social; difícilmente se podrá argumentar que mejores condiciones para la movilidad, el incremento de las transacciones de bienes y servicios y la mayor división del trabajo son fenómenos negativos, Mayor intercambio cultural, científico y tecnológico, por otra parte, contribuyen a abrir nuevos horizontes y estimulan progresos en variadas actividades. Pero la globalización genera también nuevos peligros en materia de seguridad internacional (piénsese, por ejemplo, en la producción transnacional de la energía atómica, en la venta ilegal de armamentos y el terrorismo internacional, en los problemas del narcotráfico, entre otros), y para el medio ambiente (presiones globales sobre sistemas económicos nacionales que condicionan la destrucción de aguas, tierra, aire, flora y fauna). Asimismo, la globalización favorece las migraciones internacionales, que son entendidas como un problema en muchos lugares del mundo por sus consecuencias indeseables, pero que también admiten una valoración positiva, toda vez que estimulan una toma de conciencia de la solidaridad internacional. En el campo de la cultura, los estímulos de la globalización, tanto aquellos favorables a la diversidad (por ejemplos en modos de pensar, de conducta, etc.) como aquellos favorables a la homogeneidad (por ejemplo en pautas de consumo), pueden contribuir a generar problemas de identidad o problemas de orientación en personas y grupos. Las frustraciones a que dan lugar tales experiencias pueden favorecer tendencias de reacción, propuestas fundamentalistas, étnico-nacionalistas o integristas, es decir, propuestas que pretenden abarcar a personas y grupos por completo, en todas sus dimensiones humanas.

J unto a la tendencia de acelerada globalización, ya sea como parte de la misma o bien paralelamente, se producen procesos de integración regional, institucional y/o funcional' ${ }^{1}$. Las aproximaciones institucionales entre distintos países encuentran expresión en acuerdos preferenciales entre grupos de países, constitución de zonas que aspiran al libre comercio, uniones arancelarias, etc. En las últimas dos décadas, el comercio intraregional ha adquirido especial importancia para las economías nacionales.

En la actualidad es válido, y tal vez necesario, que los países se pregunten si los procesos de regionalización constituyen realmente pasos hacia una mayor globalización, es decir, si se ve claramente una regionalización de economías abiertas dentro de un sistema económico sustentado en principios liberales, o si cabe la posibilidad que se llegue a una situación distinta, marcada

1 Bajo los conceptos de regionalismo, regionalización, integración regional o formación de bloques, podemos entender dos cosas: la aproximación político-institucional de países cercanos geográficamente, aproximación en una o más áreas, y el acercamiento más espontaneo de individuos y organizaciones de distintos países mediante transacciones (comercio, finanzas, turismo, comunicaciones, migraciones, etc.), sin existir acuerdos institucionales especiales.

2 Esta pregunta encuentra su fundamento en experiencias históricas del pasado (orden económico internacional hasta la Primera Guerra Mundial, período de guerras y de entreguerra). 
por la formación de bloques económicos regionales cerrados. En tal caso, cabe preguntar por los peligros potenciales emergentes y por las estrategias políticas preventivas. ${ }^{2}$

En relación al Estado-nación, las tendencias de globalización y regionalización producen un cambio en el concepto tradicional de soberanía nacional. La competencia del estado nacional clásico tiende a erosionarse debido a procesos y problemas que adquieren un carácter global, con independencia de las decisiones que toman estados individuales. Las instituciones supranacionales regionales y multilaterales aumentan y demandan una parte de las competencias que hasta hace poco tiempo correspondían al estado nación. ¿Significa esto que el estado nacional debe adaptarse y cambiar de funciones?; los estados nacionales ¿deben orientar sus políticas exteriores al bien común del mundo y deben relativizar los intereses nacionales individuales? En efecto, según se ha argumentado, si la interdependencia de los pueblos y de los estados aumenta aceleradamente, si muchos desequilibrios y crisis del mundo de la economía, problemas de seguridad internacional, y desafíos medioambientales, solo pueden ser superados por medio de la cooperación de todos, entonces ningún estado del mundo debiera tratar de seguir unilateralmente sus propios intereses, sin considerar los intereses de los otros. Aquí no se sugiere abandonar utópicamente los intereses tradicionales del estado nación, porque condición para hacerlo sería demostrar que las preguntas en torno a esos intereses han perdido validez; mucho más que eso, se trata de hacer el esfuerzo de entenderlos en el nuevo contexto, en relación a los temas globales que demandan cooperación.

\section{Pluralismo}

La globalización favorece el pluralismo al interior de los países. Pluralismo es más que el hecho que la sociedad se componga de muchos individuos y grupos distintos; en una sociedad pluralista las personas y los grupos se orientan por intereses que definen ellos mismos y también convicciones propias.

En la actualidad, el pluralismo tiende a darse en variadas formas de relación social: en el mundo de la economía, en la cultura y la ciencia, en materias religiosas y de visiones del mundo, en la política, y también en los estilos de vida. Condiciones favorables para el pluralismo son el despliegue de relaciones de mercado, el crecimiento económico, la mayor división del trabajo, y los procesos de diversificación y diferenciación social relacionados a todo lo anterior.

Todos esos fenómenos conducen a una creciente descentralización de las dimensiones sociales de la existencia humana (vida privada, familia, tiempo libre, trabajo y economía, cultura, ciencia, religión, política, etc.). Cada una de esas dimensiones pasa a ser independiente, sigue sus propias leyes, aun cuando esté influida por otras. En consecuencia, en cada una de esas dimensiones, las personas tienden a orientarse según distintas metas y según lo que demanden distintas circunstancias.

El pluralismo genera preguntas. Para muchos se trata de una crisis social, de un factor de desintegración, negativo para las orientaciones comunes. Es cierto que muchas personas carecen de orientación y caen en crisis frente a una sociedad que se vuelve aceleradamente pluralista. Pero pluralismo no es equivalente a desorientación o desintegración, porque se trata de un proceso que encuentra su fundamento en características naturales del ser humano (discernimiento, volun- 
tad, capacidad de transcender frente a las circunstancias, entre otras). Además, no se puede negar que la diversidad y la competencia significan mayor riqueza, no solo en bienes materiales, también en bienes culturales. La sociedad pluralista está en condiciones de ofrecer a las personas bienes culturales diversos y de generar un marco de referencia favorable para dar una dirección responsable y auto-determinada a la vida.

Nosotros debemos reconocer el pluralismo como un hecho histórico que empapa nuestras vidas, debemos saber reconocer las posibilidades que se abren y también tratar ver los peligros. Los peligros potenciales del pluralismo en la vida pública, las posibilidades de desintegración de la sociedad y la lucha abierta de todos contra todos, parecen ser evitables mediante la capacidad de entendimiento de todas las personas y fuerzas sociales en concurrencia para alcanzar una mínima medida de orden común de consenso. La sociedad pluralista debe encontrar ese consenso mínimo: reglas de consenso para la coexistencia, para la solución de conflictos; orden de consenso para la mantención y el despliegue de aquellas instituciones que son necesarias para todos; consenso básico de valores para la fundamentación de las reglas y de las instituciones, y para la cooperación humana.

En principio, la sociedad pluralista parece demandar pocos valores de consenso, pero los consensos sobre reglas y el orden común deben quedar bien garantizados. Esto es importante, porque de otro modo el orden común y todas las reglas podrían ser cambiables arbitrariamente, en todo momento. Se piensa en consensos en torno a valores esenciales o fundamentales, que no se opongan al pluralismo, respecto a los cuales todas las fuerzas sociales sean corresponsales, y naturalmente los órganos estatales de la sociedad.

¿Cuáles son los valores fundamentales que la sociedad comprendida democrática y libremente debe mantener? El valor más importante en el período contemporáneo parece ser la dignidad de la persona humana, porque esa dignidad es básica para el orden común de nuestra vida en conjunto. En el reconocimiento de esa dignidad descansa la idea de los derechos humanos como expresión del derecho de la persona al libre desarrollo en la sociedad. De ello, se siguen demandas por la tolerancia y el respeto a la diversidad.

Una sociedad que a pesar de todas sus diferencias en intereses y convicciones, se esfuerza por mantener un orden fundamentado en ese valor, y ello es reconocible en normas e instituciones de ese orden, estará en mejores condiciones de manejar su pluralismo que una sociedad que no lo haga.

\section{Democracia}

La forma democrática de gobierno ha ganado progresivamente mayor consenso a nivel internacional. En la actualidad, ordenes políticos de distinto signo no cuentan con un buen clima para su desenvolvimiento internacional.

\section{¿Qué se entiende por orden constitucional democrático?}

El estado constitucional democrático se fundamenta en el principio de la soberanía popular, esto es, todo poder del estado se origina en el pueblo. De ello emana el derecho de la colectividad a definir lo que es el bien común de la sociedad y a regular determinados aspectos en beneficio de 
todos. Pero esas regulaciones deben ser practicadas de acuerdo con la dignidad y los derechos de las personas y de los grupos sociales, es decir, bajo condición del respeto de los derechos humanos individuales de las personas, porque en ello radica otro principio fundamental del estado constitucional democrático contemporáneo. En la práctica, esto significa que el pueblo soberano se impone determinados límites legales e institucionales al darse un orden político en forma de una constitución. El pueblo queda unido a un orden, en el cual su soberanía como colectividad no lo puede todo, porque ese orden está unido a derechos humanos que son anteriores a toda forma histórica que adopten la sociedad y el estado.

Desde la perspectiva de la democracia contemporánea, como fórmula que vincula la soberanía popular y la garantía de los derechos humanos fundamentales, la forma de gobierno que adquiere el estado no puede ser neutral respecto a valores. Actualmente, hay un consenso internacional cada vez mayor respecto a la idea que el bien común en nuestro tiempo no puede ser encontrado si no es por vía del estado de derecho democrático.

En la sociedad contemporánea, crecientemente diversificada, las relaciones sociales son muy dinámicas y, en consecuencia, el orden político debe equivaler a esa realidad. Un orden político estático, centralizado y poco participativo, difícilmente podrá encontrar fundamentación y legitimidad en la sociedad. Por lo tanto, en el contexto señalado, no hay razón legítima para privar de la participación política a determinados grupos sociales, y resulta ser extremadamente peligroso entregar todos los medios de poder a una sola persona 0 a un solo grupo de personas, sin controles. Las instituciones de la participación y del control pasan a ser fundamentales para el orden constitucional democrático.

El estado de derecho democrático es el orden político que en la actualidad equivale de mejor forma a la idea de la dignidad de la persona y de los derechos humanos individuales. En nuestro tiempo predomina el reconocimiento que la persona, frente a otras personas y grupos, y frente al estado, tiene derechos naturales, no por su origen o por el hecho de pertenecer a determinado grupo social, sino por el hecho de ser una persona individual con dignidad humana. Por dignidad humana se entiende la capacidad de la persona para una autodeterminación moral, una dirección responsable de su vida y su igualdad de rango respecto a los demás. La valoración positiva de esa característica humana fundamenta la idea de igualdad política, es decir, el mismo derecho de participación de los ciudadanos en el sistema político.

En consecuencia, para una práctica genuinamente liberal de la democracia, tal vez lo más importante es la estrecha relación entre la idea de democracia entendida como soberanía popular y la idea de los derechos humanos. La protección de los ciudadanos de la arbitrariedad de los órganos estatales y la garantía del derecho al desarrollo en conjunto con otros en la sociedad son condiciones y bases esenciales de una democracia. Por lo tanto, libertad de opinión, información, prensa, asociación, coalición, reunión, libertad para la fundación de partidos y para la oposición son derechos de libertad de los ciudadanos y al mismo tiempo elementos centrales del orden democrático. De igual modo, los derechos políticos de la participación deben encontrar expresión en la reglamentación del traspaso democrático del ejercicio del poder.

En un orden democrático, todas las reglas formales son expresión de valores de la libertad y del derecho. Una práctica política que hace uso de esas reglas, aún cuando es difícil y demanda mucha paciencia, tiene mayores posibilidades de encontrar algo mejor, desde el punto de vista del 
contenido, que un régimen autoritario que esté menos unido al derecho y a las reglas. En tal sentido, los principios, las instituciones y las reglas del estado constitucional democrático están estrechamente relacionados y constituyen un elemento esencial del bien común, es decir, del buen orden político de nuestra sociedad.

\section{ELEMENTOS DE LA NOCIÓN DE ESTADO DEMANDADA EN NUESTRO TIEMPO Y PRINCIPIOS NORMATIVOS PARA LA ORIENTACIÓN DE FUNCIONES Y REGULACIONES ESTATALES}

Ahora esta reflexión se orienta a proponer elementos de una noción de estado que sean coherentes con las megatendencias condicionantes a que hemos aludido, y principios normativos que deben orientar las funciones y regulaciones del estado. ¿Cómo hemos de concebir al estado, si éste ha de tener capacidades de responder positivamente a los desafíos de la globalización, del pluralismo y de la democracia?

Independientemente de la forma concreta que pueda adoptar el estado al finalizar el siglo XX, reconocemos como fundamento esencial del mismo la comunidad de ciudadanos; el estado es expresión de comunidad de los ciudadanos, es la sociedad en su forma de comunidad política, y solo puede existir mediante el consentimiento de quienes integran esa comunidad. Ese consentimiento no está dado a priori o por naturaleza, demanda como condición necesaria el permanente proceso dinámico de formación de la comunidad, y por lo tanto demanda procesos de integración que estimulen a las personas para seguir participando en un proyecto común. Entrando hacia el siglo XXI, en una sociedad más globalizada, pluralista y democrática, este fundamento del estado debe estar presente, en calidad de criterio de evaluación, al momento de preguntar por funciones que debe cumplir el estado o por reformas que ha de experimentar el estado, entendido como sistema político central de decisiones.

El mayor campo de regulación del estado es una razón bien concreta para demandar un orden político-institucional que, fundamentado en la noción de estado como comunidad de ciudadanos, brinde amplias posibilidades de controles institucionales del poder político y favorezca los derechos de participación política de los ciudadanos. El estado de la sociedad contemporánea, más que nunca antes, tiene consecuencias en todas las áreas y las relaciones humanas; la economía y las actividades sociales, la ciencia, la tecnología y la protección del medio ambiente, el desarrollo cultural, incluso la familia, el tiempo libre, el deporte, etc. demandan actualmente no solo un contexto legal por parte del estado, sino también una actividad del estado, apoyo del estado. Naturalmente se puede discutir, según el principio de subsidariedad y las condiciones concretas de cada sociedad, hasta qué punto es necesaria la actividad del estado. Pero fuera de toda duda, es el hecho que en el estado de fines del siglo XX el bien común no queda solo as egurado por un marco que garantice el derecho y la paz. Si el estado ha tomado tantas funciones en las diversas áreas de la vida social, entonces la sociedad, en forma de ciudadanos individuales y asociaciones intermedias, debe tener la posibilidad de influir en la actividad de los órganos del estado, de determinar, controlar y corregir esa actividad. De este modo, mayores regulaciones por parte del estado demandan mayor participación de los ciudadanos en el orden político e institucional.

La comprensión del estado como sociedad en forma de comunidad política no significa afirmar que el estado y la sociedad sean idénticos. El estado es la sociedad en su unidad política y 
jurídica, pero la sociedad se desarrolla no solo políticamente, también en muchas otras dimensiones (cultura, religión, economía, etc.). En esas dimensiones, la sociedad debe ser sociedad libre, y el estado debe cumplir una función de orden común.

Si se pregunta de manera muy precisa por la tarea o finalidad concreta del estado, aquella labor que debe cumplir, sin inhibir las posibilidades de despliegue de las personas y de las fuerzas sociales que le fundamentan, es posible postular como meta del estado el bien común, entendido como orden que promueva y garantice la existencia de condiciones favorables para el desarrollo de las personas en su dimensión individual y en los grupos sociales a que pertenecen. Pero la pregunta por lo que corresponde a esa función de bien común del estado, de manera concreta en cada sociedad, no es fácil de responder, de modo tal que sea generalizable. Debe ser encontrado por las personas y los grupos sociales según las circunstancias históricas y culturales de cada sociedad; por esta razón, en el curso de la historia, los estados pueden adoptar diversas metas específicas para el cumplimiento de su finalidad.

Dando debida atención a los movimientos de larga duración ya reconocidos y fundamentados que condicionan nuestras acciones, es posible postular una función estatal imprescindible para el bien común en nuestro tiempo. A saber, el estado tiene la tarea tradicional de posibilitar y de garantizar nuestra vida en común, pero dentro de un marco de respeto por la variedad y las diferencias en la sociedad. En otras palabras, en la actualidad, un orden estatal de derecho y de paz estará en condiciones de ganar nuestro consentimiento si no se convierte en un fin en sí mismo, sino que sirve para el despliegue de nuestras variadas potencialidades personales y de grupos en una sociedad crecientemente afectada por la globalización, el pluralismo y la democracia. El orden social externo de la coexistencia, externo al individuo o a los grupos de personas, unido al respeto y la valoración de la variedad y de las diferencias, debe ser garantizado por el estado, y la forma de sus instituciones y sus regulaciones deben ser expresión de ello.

Del creciente pluralismo en nuestra sociedad, se genera una demanda para que los órganos estatales hagan un aporte en orden a llegar a cosensos fundamentales o básicos de coexistencia, y por cierto deben defender esos consensos. No se trata de demandar orientaciones de valores, porque los órganos estatales deben ser neutrales en materia de ideas de mundo, convicciones, creencias e intereses específicos. Pero el estado es co-responsable por una mínima medida de consenso de valores en el sentido de un deber por el bien común; a estos valores de consenso, en una sociedad que se vuelve pluralista, corresponderá respeto y la valoración de la variedad y de las diferencias.

Al cumplir su función de promover y garantizar consensos fundamentales o básicos de coexistencia, los órganos del estado y sus instituciones podrán tener consecuencias en los comportamientos de las personas, consecuencias estabilizadoras y ordenadoras de la vida en una sociedad que se va volviendo globalizada, pluralista y democrática. En este sentido, los órganos estatales y las instituciones del estado serán corresponsables de los consensos básicos de la sociedad.

Los consensos fundamentales que el estado debe proteger expresan valores compartidos en la sociedad; si en nuestro tiempo el estado debe proteger un orden público que sea garantía de respeto por la variedad y las diferencias en la sociedad, y para ello puede hacer uso de sus medios de fuerza, ello significa que la sociedad valora ciertos bienes de derecho, tales como 
dignidad humana, vida, libertad, entre otros; si el estado debe desarrollar una política social, ello expresa que la sociedad valora un mínimo de bienestar de las personas, el cual debe quedar garantizado.

Algunos de los valores de consenso o valores fundamentales y principios relacionados con esos valores son declarados en la constitución política del estado. Por lo tanto, los órganos estatales estarán obligados a defender esos valores y principios. Asimismo, deberán preguntar si aquello que las fuerzas sociales quieren realizar se deja unir con los principios de la constitución del estado.

Entendiendo ahora al estado como una dimensión o esfera política de la sociedad, cuyas tareas fundamentales consisten en garantizar un buen orden común que, en el contexto de mayor globalización, pluralismo y democracia, evite la guerra de todos contra todos, facilite la coexistencia, sea condición favorable para la realización de valores compartidos, y por lo tanto estimule la integración, preguntamos por principios normativos orientadores de acción estatal. A continuación se argumentará a favor de tres principios: solidaridad, bien común y subsidariedad.

\section{Solidaridad}

La idea de la solidaridad encuentra fundamento en las dependencias recíprocas o la relación de interdependencia de las personas. Las personas se necesitan mutuamente, están vinculadas porque sólo de ese modo se pueden desarrollar. Desde esta perspectiva, todas las instituciones y reglas de la sociedad pueden ser consideradas expresión de solidaridad, en cuanto sean expresión de la interdependencia de las personas y sean realmente condiciones favorables para el desarrollo de las mismas.

La solidaridad contiene una demanda de carácter normativo, porque de las dependencias recíprocas de las personas se siguen deberes recíprocos; estos son válidos en todas las comunidades a las cuales pertenecemos, en tres direcciones: como deberes de responsabilidad de individuos y de grupos en sus relaciones recíprocas, de los individuos y grupos respecto al estado, y del estado respecto a los individuos y grupos. Del principio de la solidaridad se sigue que cada miembro de una sociedad es co-responsable por el bien común, y cada comunidad es responsable por el bienestar de sus miembros.

La solidaridad como principio orientador no debe ser mal interpretada. No niega el derecho de cada cual a orientarse según su interés individual, no termina con la competencia de diversos intereses en la sociedad. La solidaridad solo demanda que en el contexto de la competencia y de los conflictos también haya intereses colectivos, es decir, reglas del juego que expresen un reconocimiento recíproco. Solidaridad no demanda la renuncia a la afirmación propia individual, porque la persona no puede perder su individualidad en lo colectivo; hacerlo sería hacer una negación de la propia naturaleza. Pero la solidaridad prohibe la afirmación inescrupulosa y egoísta de intereses particulares. La solidaridad demanda la toma de conciencia ordenada de los intereses, en el horizonte de un interés general o bien común.

De lo anterior se sigue que la solidaridad no puede servir de fundamento para tratar de limitar el libre espacio de cada cual, la iniciativa privada, la propiedad privada y la responsabilidad de las personas, con el objeto de ampliar las competencias y actividades del estado, la propiedad públi- 
ca, y las reglas de competencia para las autoridades administrativas. La solidaridad no justifica acciones 0 regulaciones destinadas a limitar 0 a sustituir la independencia y responsabilidad de las personas y de los grupos intermedios, y a dificultar la fundación de existencias independientes.

Para que lo común tome una forma concreta, es necesario un orden legal y organizador. La solidaridad no se limita a una simple vinculación de las personas motivada por su actitud moral individual, sino que se concretiza también en el lado organizativo y legal. Una de las tareas centrales del estado consiste en traducir algunos de nuestros deberes de solidaridad en forma de leyes, pero no todos los deberes. El estado de derecho debe limitarse a fijar mediante reglas comunes los deberes fundamentales para la vida ordenada en sociedad, y a esto corresponderán todas aquellas regulaciones que sean necesarias para que las personas efectivamente tengan garantizadas las posibilidades para su desarrollo en la sociedad. Por otra parte, el respeto de los ciudadanos por las leyes comunes es expresión de la solidaridad.

En el caso de Chile, la Constitución Política es el orden legal y organizador básico que sirve como concreción del principio y de pauta orientadora. El Capítulo III de nuestra Carta Fundamental "De los Derechos y Deberes Constitucionales", en armonía teórica con los primeros artículos que tratan sobre "Las Bases de la Institucionalidad", los cuales marcan la estructura por la cual debe orientarse todo nuestro sistema normativo-jurídico, nos da cuenta de una serie de derechos y deberes que han sido garantizados por el Legislador, a fin de propender a un orden común y a una convivencia pacífica entre los miembros de la sociedad toda, incluyendo a los órganos del estado; de hecho, todos sin excepción, individuos aislados y máximos órganos gubernamentales, deben someter su acción a lo prescrito por la Constitución, tal como lo señala el art. 6 de la misma³ .

Entonces, podemos concluir en una primera aproximación, que la Constitución debe ser el marco regulatorio básico, el orden legal y organizador de la solidaridad; debiera ser en definitiva el mínimo de consenso requerido, en torno al cual se desplegarán las tareas del Estado, los movimientos de larga duración y la actividad particular de grupos intermedios y de los individuos.

Finalmente, el principio de la solidaridad tiene como consecuencia política que todos los ciudadanos seamos, en última instancia, responsables ante acciones que cometan nuestros órganos 0 representantes en nombre de nosotros. En consecuencia, expresión de solidaridad será un estado donde los ciudadanos realmente tengamos participación.

\section{Bien común}

Si cada persona necesita de los demás para su propio bienestar, entonces nosotros podemos producir los bienes que necesitamos solo en conjunto. Por esta razón, las relaciones sociales no son solo de conflicto entre intereses contrapuestos, también relaciones que sirven a todos.

Para que los intereses distintos puedan coexistir, para que sea posible llegar a acuerdos mínimos, y finalmente también a valores compartidos, toda sociedad necesita algún tipo de orden común. Ese orden deberá brindar protección y posibilitar una toma de conciencia ordenada de los intere-

3 "Los órganos del Estado deben someter su acción a la Constitución y a las normas dictadas conforme a ella. Los preceptos de esta Constitución obligan tanto a los titulares o integrantes de dichos órganos como a toda persona, institución o grupo. La infracción de esta norma generará las responsabilidades y sanciones que determine la ley". 
ses, y al mismo tiempo deberá poner límites a la absolutización de intereses particulares, en cuanto esa absolutización signifique una amenaza para el orden común y para las metas de ese orden querido por todos.

En consecuencia, el bien común en sentido estricto será entendido como orden común de la sociedad, esto es, reglas, instituciones, y órganos que son necesarios para que los intereses comunes puedan ser alcanzados.

Al mismo tiempo, el bien común se traduce en las tareas para las cuales el Estado existe, tal como indica el art.1 de nuestra Constitución que declara en su inciso 4: "El Estado está al servicio de la persona humana y su finalidad es promover el bien común, para lo cual debe contribuir a crear las condiciones sociales que permitan a todos y a cada uno de los integrantes de la comunidad nacional su mayor realización espiritual y material posible, con pleno respeto a los derechos y garantías que esta Constitución establece". Bien común significa todas aquellas condiciones que permitan alcanzar las metas indicadas en el texto citado.

Lo anterior no significa que el estado debe realizar todo el bien común, es decir, los bienes y valores que son aspirados en la sociedad (económicos, sociales y culturales). Eso es asunto de las personas y grupos en la sociedad. Pero el estado, en relación a todos los bienes y valores a realizar, tiene una tarea de bien común, por cuanto debe garantizar condiciones políticas de orden para que los seres humanos se puedan desarrollar; debe proteger el derecho y garantizar la paz, los derechos humanos y la diversidad.

En la actualidad, un orden de derecho y de paz está en condiciones de ganar nuestro consentimiento cuando no se convierte en un fin en sí mismo, sino que sirve para el despliegue de nuestras potencialidades personales en la sociedad, y para esto el derecho y la seguridad son condiciones necesarias. Cuando el orden social externo de nuestra coexistencia, externo al individuo 0 a los grupos de personas, no está garantizado, cuando ese orden experimenta una crisis, queda de manifiesto cuan fácil es que nosotros caigamos en una guerra de todos contra todos.

Fuera de la función central descrita, es posible postular tareas de bien común del estado en todas las áreas, en las cuales la vida de una sociedad se despliega. El estado puede ser también un estado social y cultural, es decir, puede generar condiciones legales para el despliegue de potencialidades económicas, sociales y culturales, y según la situación también debe apoyar y contribuir a cambios estructurales. Pero siempre queda en la sociedad la concreta determinación del bien común como tarea a descubrir según lo que la situación demande con sus posibilidades y límites.

En una sociedad crecientemente pluralista, pluralista en intereses y valores, a veces cuesta tomar conciencia de la importancia que tienen las reglas formales del bien común, y de lo difícil que resulta encontrarlas. Cuestiones como las siguientes son de difícil solución: ¿Quién puede decidir obligatoriamente? ¿cómo se producen las decisiones? ¿cómo podemos participar? ¿cómo es posible el control y la seguridad contra el mal uso del poder? En consecuencia, en nuestro tiempo los principios, instituciones y reglas del estado de derecho pacífico son elementos fundamentales del bien común. Esos valores formales son irrenunciables, esos elementos de orden formal del estado son al mismo tiempo expresión y protección de determinados valores con contenido. 


\section{Subsidiariedad}

Las personas son portadoras, creadoras y, al mismo tiempo, meta de todas las instituciones sociales, y no la sociedad o el estado. En consecuencia, las mismas personas y sus asociaciones deben determinar la orientación y la dirección de los procesos sociales. Para que ello sea posible, el orden social debe servir de estímulo para el desarrollo de las personas en libertad. De esa comprensión de la persona y de la sociedad se sigue la demanda de una estructura subsidiaria del edificio social. Las personas y las comunidades tienen el derecho a realizar sus metas y tareas mediante su propio esfuerzo. Solo cuando pueden desarrollar sus actividades en base a su propia iniciativa, autodeterminación y responsabilidad, y no son reglamentadas 0 dirigidas por sociedades mayores o por los órganos estatales, entonces queda garantizado el principio. Pero, cuando una persona 0 un grupo no está en condiciones de alcanzar sus metas, y necesita estímulo y apoyo, entonces puede tener la pretensión de recibir ese apoyo de la sociedad y sus órganos estatales.

El principio de subsidiariedad es una regla fundamental para la fijación de las competencias en la realización del bien común. Lo que el individuo o la asociación intermedia puede alcanzar mediante su propio esfuerzo no debe ser asumido por la sociedad o el estado. El principio presenta una defensa de la libre iniciativa en la sociedad, se declara por el derecho de los individuos y pequeños círculos para la construcción de los órdenes sociales desde abajo hacia arriba.

La subsidariedad encuentra expresión en las bases de la institucionalidad, declaradas por la Constitución Política de 1980, en su artículo 1: "El Estado reconoce y ampara a los grupos intermedios a través de los cuales se organiza y estructura la sociedad y les garantiza la adecuada autonomía para cumplir sus propios fines específicos".

A este principio no se puede apelar como fundamento para limitar lo más posible la actividad del estado, 0 incluso poner en tela de juicio la soberanía del estado en determinadas materias. No se trata de postular un estado débil o el derecho absoluto de las personas y las asociaciones intermedias frente al estado. El principio apunta a garantizar las propias tareas y áreas de competencia de grupos y comunidades, y demanda del estado ser subsidiario en caso de necesidad.

Cuando se piensa en las implicaciones prácticas del principio de subsidiariedad, es conveniente pensar en forma cualitativa: competente para cumplir funciones y tareas es, en primer lugar, la agrupación más cercana a la persona, es decir, aquella que está en mejor situación para brindar mejor la ayuda para la autoayuda; es mejor el apoyo de las comunidades más pequeñas, a las cuales la persona se siente más vinculada, que una ayuda anónima y desde arriba, pensada en general.

Bajo condiciones de mayor pluralismo social, el principio de la subsidiariedad da un fundamento para la idea que el orden político posibilita la libertad de personas y grupos, y que debe protegerla.

\section{REFLEXIONES FINALES: ALGUNAS INTERROGANTES PARA LA INVESTIGACIÓN}

Identificadas y precisadas tres de las megatendencias que nos están afectando, expuestas algunas indagaciones sobre la noción de estado que demanda nuestro tiempo histórico y sobre princi- 
pios normativos orientadores para que el estado esté en condiciones de cumplir funciones de integración, a continuación se proponen algunas interrogantes para la investigación.

¿Es nuestro orden normativo-institucional favorable o desfavorable para la integración nacional? ese orden, ¿favorece u obstaculiza el despliegue de los procesos de globalización, pluralismo y democracia? ¿Está Chile preparado en sus estructuras, instituciones y marco normativo-jurídico para aprovechar las posibilidades y enfrentar los desafíos que imponen la globalización y el pluralismo? La pregunta es compleja y demanda una investigación de dimensiones ${ }^{4}$.

Nuestro orden institucional contiene elementos centrales del estado constitucional democrático (soberanía popular y derechos humanos)5. Como en ese orden las instituciones de participación y del control pasan a adquirir gran significado, cabría preguntar por las bondades de nuestro actual sistema electoral: ¿favorece dinámicas de participación coherentes con los efectos de la globalización y el pluralismo en la sociedad? ¿es realmente un sistema que refleja las preferencias de los ciudadanos con derecho a voto? ¿permite efectivamente que todos los grupos políticos encuentren representación, y en consecuencia se sientan integrados?

Respecto a los derechos humanos, las disposiciones constitucionales y legales que declaran y garantizan la dignidad humana en nuestro país ${ }^{6}$ ¿tienen consecuencias reales? ¿La incuestionable falta de igualdad de oportunidades sociales y económicas en Chile permite hablar de igualdad de trato y de dignidad?, en esta materia, ¿qué correspondería hacer al Estado y qué correspondería hacer a otros actores individuales y colectivos de la sociedad? Con relación al tema, grandes reformas de la actualidad, tales como la reforma judicial, ¿se insertan en un proceso integral de reformas y acciones estatales o entran en contradicción con prácticas, instituciones y regulaciones que no promueven la toma de conciencia y el uso de derechos entre los ciudadanos?

En Chile, como en otros países del mundo, es necesario el equilibrio entre un amplio espacio para libre desarrollo de los individuos y condiciones sociales e institucionales que garanticen una convivencia fructífera en la sociedad. La globalización y el pluralismo pueden tener el efecto de estimular en las personas un énfasis sobredimensionado en la realización personal, y ello puede texto constitucional es el reconocimiento de los derechos humanos, consagrados en la Carta y en los Tratados internacionales sobre la materia (art. $5^{\circ}$ inc. $2^{\circ}$ ). En el ámbito económico-comercial, parecieramos no estar tan lejanos, pues nuestra Constitución consagra una serie de disposiciones con relación a la libertad económica y orienta el marco jurídico donde esta actividad se desenvuelve, por medio de leyes tales como la de Inversión Extranjera, Mercado de Valores, Sociedades Anónimas y Antimonopolio, entre otras, todas las cuales son elementos claves para una política de integración económica-financiera a nivel internacional.

5 En Un Estado democrático, según hemos argumentado más atrás, se fundamenta en el principio de soberanía popular, y ese principio se encuentra consagrado en nuestra Constitución a través de dos disposiciones básicas: art.4 "Chile es una república democrática", y el art.5 inc.1 "La soberanía reside esencialmente en la Nación. Su ejercicio se realiza por el pueblo a través del plebiscito y de elecciones períodicas y, también, por las autoridades que esta Constitución establece. Ningún sector del pueblo ni individuo alguno puede atribuirse su ejercicio." Pero, al mismo tiempo, la soberanía debe reconocer límites en su ejercicio, porque el orden que ella establece está unido a derechos humanos que son anteriores al Estado; esto lo encontramos en dos artículos de la Constitución: el art.1, inc. 4 primera parte, nos da una referencia indirecta al señalar que "El Estado está al servicio de la persona humana (...)", y por otra parte el art. 5 inc. 2 nos dice expresamente: "El ejercicio de la soberanía reconoce como limitación el respeto a los derechos esenciales que emanan de la naturaleza humana (...)". Por otra parte, los derechos humanos son expresamente reconocidos y garantizados (arts. 1 y 19).

6 Disposiciones del art. 19; recursos fundamentales consagrados para resguardo de derechos y deberes en arts. 20,21 y 80. 
producirse a costa del desarrollo de una conciencia equivalente sobre los deberes políticos y sociales. De estar dándose ese problema en nuestro país ${ }^{7}$, y pensando en las consecuencias negativas que ello puede tener para la integración nacional, ¿sería legítimo demandar acciones especiales por parte del estado? acciones que, lejos de pretender inhibir los procesos de globalización, pluralismo y democracia, signifiquen una contribución para restaurar el equilibrio; se piensa, por ejemplo, en el papel que podría caber al estado en la formación ético-política de la ciudadanía. ${ }^{8}$

La idea de "identidad nacional" y sus consecuencias, esto es, instituciones y regulaciones comunes, corren el peligro de perder el consentimiento de los ciudadanos si mantienen el carácter de ser expresión de un orden social, económico y cultural que entra en contradicción con una sociedad que se va volviendo globalizada, pluralista y más democrática en intereses y valores. Aquellas formas de instituciones y regulaciones que no experimenten el necesario proceso de renovación y adaptación, serán objeto de un creciente cuestionamiento por parte del ciudadano común, y dejarán de ser expresión de consenso. En consecuencia, no brindarán un servicio para la integración. ¿Es este un criterio válido para abordar el tema de la modernización del estado?

En la actualidad, el concepto de nación puede pasar a quedar subordinado a valores más elevados o generales que en el pasado, a principios de consenso. Dentro de la nación hay diversas relaciones entre las personas, las que dan origen a derechos y deberes, tales como deberes de solidaridad respecto a determinadas comunidades a las que se pertenece libremente. En general, esas relaciones y deberes no entran en conflicto con la vinculación simultánea de las personas a la nación. Pero de producirse conflictos, los órganos estatales no tienen derecho de demandar de sus ciudadanos más aquello que sea necesario para el bien común o el orden común integrador, y ello debe estar fundamentado (defensa de la variedad, diversidad, derechos humanos, igualdad de oportunidades, etc.). Si se sostiene que hay una demanda del bien común, entonces el bien común debe estar claramente expresado en deberes de derecho, que no entren en contradicción con los derechos de las personas y sus asociaciones. Resultará extremadamente inconveniente argumentar con la idea vaga de una identidad nacional, de integración nacional o en base a intereses corporativos. Aquí puede radicar un principio orientador medular para emprender una investigación sobre la demanda contemporánea por modernización de las instituciones públicas.

Con relación al principio de subsidariedad, orientación normativa para las acciones integradoras del Estado, cabe hacer las siguientes reflexiones y preguntas:

Por razones de cultura política o de otro tipo, si la mayor parte de los ciudadanos tiene la tendencia a la pasividad o permanece inerte frente a determinados temas y propósitos reconocidos como de interés público, esperando que el Estado disponga todo, ¿cabría demandar de los órga-

7 Probablemente sean expresión del mismo, temas contingentes que preocupan al mundo político e intelectual chileno, tales como la probidad y transparencia en el ejercicio de las funciones públicas, e incluso en el campo de la empresa privada, la falta de motivación en la juventud por la participación en la vida política de su país, y asimismo otras multiples dificultades en la vida cotidiana (por ejemplo la delincuencia).

8 Mayor fundamentación y antecedentes sobre el tema en Patricio Valdivieso, Ein Weg zur Sozialreform in Lateinamerika: Die Rezeption der katholischen Soziallehre Europas in Chile, vol. 7 de serie Historamericana, Verlag Hans-Dieter Heinz, Akademischer Verlag (ISBN 3-88099-676-8), Stuttgart 1998, 451 págs; del mismo autor, "Ética Política y Éxito Moral" en: Revista de Ciencia Política, XIX (2), 1998, 3-44. 
nos estatales acciones especiales para que los ciudadanos salgan de la inercia? Pensando, por ejemplo, en el tema de la participación ciudadana, ¿se podría esperar del Estado acciones especiales o regulaciones orientadas a estimular la participación ciudadana, por ejemplo una legislación bien pensada sobre financiamiento de partidos políticos??

A propósito de las consencuencias de la globalización y el pluralismo, otra pregunta relacionada con el principio de la subsidariedad: ihasta qué punto debe el Estado permanecer con determinadas funciones que, aunque pudieran ser llevadas a cabo por los particulares, por su naturaleza han sido tratadas hasta ahora a nivel estatal?; se piensa, por ejemplo, en las áreas de Defensa y de la seguridad interior del Estado, en el manejo de las relaciones exteriores, en programas sociales en favor de los sectores más desprotegidos de la sociedad, etc.

Las tendencias de la globalización y del mayor pluralismo, ya descritas, y la creciente relativización de la dimensión estado-nación, pueden conducir a que las vinculaciones emocionales de muchas personas a la nación y al país como un todo, lleguen a ser apolíticas. En la actualidad, en muchos lugares del mundo se observa una mayor orientación de las personas hacia espacios nacionales más reducidos, tales como el pueblo, la ciudad de origen o la región, y es posible que los movimientos de larga duración ya descritos - globalización, pluralismo y democracia- lleguen a tener esa consecuencia en nuestro país. En caso que tales conductas de los chilenos pasaran a ser habituales, se irá abriendo mayor espacio para que nosotros nos orientemos en el campo de preguntas sobre decisiones políticas por principios de validez general y por valores como los derechos humanos fundamentales y el pluralismo, y que preguntemos por el papel positivo 0 negativo que desempeña, desde este punto de vista, nuestra estructura político administrativa nacional y regional.

Finalmente, en relación a los efectos de la globalización y el pluralismo en Chile, cabe preguntar de forma sistemática por actores tradicionales y emergentes que demandan acciones integradoras del estado, por ejemplo la institución familia sometida a condiciones de mercado, los pueblos indígenas, y las comunidades de inmigrantes latinoamericanos (bolivianos, peruanos y ecuatorianos, especialmente), entre otros.

\section{APÉNDICE DE FUENTES SOBRE EL TEMA}

\section{Centro de Estudios Públicos. C.E.P}

En términos generales, hay artículos aislados o relacionados que podrían llegar a interesar en ciertos aspectos específicos relacionados con el tema del estado y la integración. Estos artículos pertenecen a la Revista de Estudios Públicos que edita el Centro.

1) Reflexiones en torno a las condiciones del orden democrático y el cambio social, № 39 .

2) Cambio Social y Democracia. José J oaquín Brunner. №39 -1990.

9 También se podría pensar en una actividad estatal que se tradujera en mayor cantidad de información para los ciudadanos, tanto a nivel de campañas electorales, como en los períodos intermedios, lo que probablemente facilitaría una mayor participación, y además que esta sea más responsable. 
3) Reflexiones en torno a las condiciones del orden democrático y el cambio social. № 39.

4) Modernización y democratización: un dilema del desarrollo chileno. Norbert Lechner. № 70 otoño 1998.

5) Nuevas dimensiones en la política chilena. Roberto Méndez. № 45 - verano 1992.

6) Corrientes y dimensiones políticas en Chile: Comentarios al estudio de Roberto Méndez. Nº45 - verano 1992.

7) Modernización de las comunicaciones y democratización de la política: los medios en la transición a la democracia en Chile. Eugenio Tironi y G. Sunkel. N52 - primavera 1993.

8) Algunas claves de la Transición política en Chile. Oscar Godoy A. №38 - otoño 1990.

9) Descentralización y habilitación: Un desafío de política social. Pablo J ordán. N 59 - invierno 1995.

10) Algunas reflexiones sobre política social y pobreza. Eugenio Tironi. № 59 -1995.

11) Habilitación, pobreza y política social. Pablo Jordán. № 59 -1995.

12) Infraestructura: Regímenes estatales y privados en Chile. $N^{\circ} 49$.

13) La consolidación de la democracia y del desarrollo en Chile: Desafíos y tareas. Osvaldo Sunkel. N 48 - 1992.

14) La redemocratización política en Chile. Transición, inauguración y evolución. Manuel Antonio Garretón. № 42 - otoño 1991.

14) Potenciar al ciudadano: el rol de las estructuras intermedias en las políticas públicas. Peter Berger, Richard Nehaus. № 49 - 1993.

15) Políticas sociales: ¿Qué queremos en realidad? № 47 - 1992.

16) Promoción del desarrollo social privado a nivel local: una propuesta. Nㅜ 38 - 1990.

17) La mezcla pública-privada. Una reforma pendiente en el sector salud. César Oyarzo. № 55 1994.

18) Tendencias mundiales en el financiamiento de la salud. Brian Abel-Smith. № 55 - 1994.

19) Subsidios a la demanda en salud: una alternativa viable. Rafael Caviedes. № 54 - 1994.

20) Desafíos del medio ambiente y respuestas políticas. Ernst Von Weizäker. N 68 - 1997

21) Bases conceptuales y marco de referencia para la elaboración de políticas ambientales en América Latina. Ricardo Katz, Gabriel Del Fávero, Leonel Sierralta. № 57 - 1995.

22) Desarrollo de una red de transporte estratégica mediante el financiamiento privado: el caso de la ciudad de Santiago. Marcial Echeñique. №67 - 1997.

23) Los requisitos de una política global de infraestructura vial. Michael Klein. № 65 - 1997.

24) Algunas consideraciones sobre el desarrollo de la infraestructura en Chile. Marcial Echeñique. No 62 - 1996.

Asímismo hay unos documentos de trabajos denominados "Puntos de Referencia" que abordan demandas emergentes hacia el estado ( ${ }^{\circ}$ S 191, 193, 198, 199 y 200). 


\section{Instituto Libertad y Desarrollo}

Libros:

1) 1991-Soluciones Privadas a Problemas Públicos. Cristián Larroulet.

2) 1991-Ecología de Vanguardia. Una agenda para el futuro. Editado por Libertad y Desarrollo.

3) 1994-Políticas Sociales y Económicas para una sociedad libre. Cristián Larroulet.

4) 1994- Modernización del sistema carcelario. Libertad y Desarrollo, y Paz Ciudadana.

\section{Publicaciones Periódicas:}

Serie "Opinión programa político-institucional". Existen una serie de artículos que de alguna manera se acercan al tema en cuestión, en áreas tales como medio ambiente, educación y seguridad ciudadana.

a) Iniciativas para combatir la delincuencia: 3 de agosto de 1990.

b) Aportes a la solución del problema de la delincuencia: 1 de marzo de 1991.

c) Modernización del sistema electoral: el voto electrónico: sept. 1997

d) El aporte privado al desarrollo social: agosto 1997

e) Los desafíos de la modernidad y la organización social del siglo XXI.

f) Financiamiento compartido: más recursos para la educación: 3 de enero de 1997.

g) Para una adecuada reforma judicial: 18 de julio de 1997.

h) Los principales desafíos de la sociedad libre en el siglo XXI: 22 de junio de 1998.

\section{Centro de Análisis de Políticas Públicas. C.A.P.P. U. de Chile}

\section{Libros:}

1) La Reforma del Estado y las Políticas Públicas. Luciano Tomassini. 1994.

2) ¿Qué espera la sociedad del gobierno ? Luciano Tomassini. 1994

a) Democracia, desarrollo y modernización del Estado. J aime Lavados.

b) La gobernabilidad y la modernización del Estado democrático. Fernando Zumbado.

c) Desarrollo Social y Reforma del Estado: Algunos temas de reflexión. Raúl Urzúa.

d) Diseño y Evaluación de sistemas públicos: una proposición. Carlos Vignolo y Carlos Vergara.

e) Educación y Pobreza: La experiencia reciente en Chile. Ricardo Lagos.

f) Reforma del sector salud, satisfacción del consumidor y contención de costos. J orge Katz y Ernesto Miranda.

g) El papel del sector privado. Enrique U. Iglesias.

h) La Construcción social de la democracia. Cecilia Montero.

3) Cambio Social y Políticas Públicas. Editor: Raúl Urzúa. Agosto de 1997.

a) Proceso de globalización: sus impactos sociopolíticos. Luciano Tomassini. 
b) Integración transnacional y desintegración nacional en Latinoamérica y Asia: una revisión. Osvaldo Sunkel y Michael Mortimore.

c) Políticas Públicas y la globalización económica. Ricardo Ffrench-Davis.

d) Globalización, modelo económico y transformación social: una mirada parcial. Raúl Urzúa.

e) Actores, acción colectiva y participación en el campo de las políticas públicas. Emilio Tenti Fanfani.

f) Democratización y políticas públicas. Augusto Varas.

g) Notas sobre la integración de políticas sociales y políticas económicas. Felipe Portocarrero Suárez.

h) La gerencia de políticas y programas sociales. J osé Sulbrandt.

\section{Artículos:}

1) Estado, gobernabilidad y desarrollo . en el Príncipe: Revista de Ciencia Política. 1995 Bs. As. Luciano Tomassini.

2) El proceso de globalización y sus impactos socio-políticos. Luciano Tomassini en Universidad Simón Bolívar, Integración solidaria: América Latina en la Era de la Globalización, Caracas, 1996.

Documentos de Trabajo:

1) El proceso de globalización: sus impactos socio-políticos. Documento № 2 - 1995.

2) Gobernabilidad y políticas públicas. Luciano Tomassini. Documento № 21-1996.

3) ¿Cómo estabilizar una democracia entrecortada?: Una discusión entre procedimientos y valores. Hugo Quiroga. Doc. № 26 -1996.

4) Democracia y nueva articulación entre privado y público. El problema de la participación femenina y la constitución de "Espacios públicos". Pepi Patrón Doc. № 28-1996

5) Chile en el siglo XXI: Algunas consecuencias políticas de los cambios demográficos. Raúl Urzúa. Doc. № 39 - 1997.

6) La política hacia la infancia en Chile: antecedentes, tendencias actuales, propuestas. Manuel Antonio Garretón. Doc. № 40 -1997.

7) Políticas públicas sectoriales en el marco de un Estado subsidiario. Raúl Urzúa Doc. № 42 1997.

\section{Revista de Ciencia Política P.U.C:}

1) Empresarios, transición y consolidación democrática en Chile. Alfredo Rehren - 1995.

2) ¿Reforma o status quo? Dilemas y desafíos del Estado en Chile. Jorge Heine -1993.

3) Chile en Transición: estrategia económica y política. Oscar Muñoz y Carmen Celedón - 1993.

4) Gestión pública en la "era de la gestión". Carlos Vignolo - 1993.

5) Gestión pública para el desarrollo nacional. Eugenio Lahera - 1993. 
6) Regulaciones y políticas públicas. Eugenio Guzmán - 1993.

7) Políticas sociales: la reforma pendiente. Bernarda Gallardo y Michael Moure - 1993.

8) La cuestión de la transición. Oscar Godoy Arcaya - 1994.

9) Transición incompleta y régimen consolidado. Manuel Antonio Garretón - 1994.

10) La transición ha terminado. Carlos Huneeus M. - 1994.

11) La transición chilena en los años 80: claves de una transición exitosa en perspectiva comparada. Enrique Cañas Kirby - 1994.

\section{Universidad Alberto Hurtado / ILADES}

\section{Revista Nueva Sociedad (ILADES):}

\section{Artículos:}

1) Las condiciones de la democracia. Chile. Tomás Moulian. № 140 - 1995.

2) Globalización, estado nacional e instancias locales de poder en América latina. Claudete de Castro Silva y Tina Margarete Keinert. Nº 142 - 1996.

3) Globalización y sociedad civil en los procesos de integración. Andrés Serbin. № 147 - 1997.

4) Chile hoy. paradigmas y antinomias. Antonio Cortés Terzi. № 151 - 1997.

5) Relaciones Estadoempresarios, en una economía global. El caso de Chile. Cecilia Montero. $\mathrm{N}^{\circ} 151-1997$.

6) Cultura y discriminación social en la época de la globalización. N 152 - 1997

7) El valor simbólico de los economistas en la democratización de la política chilena. № 152 1997

8) Cumbre regional para el desarrollo político y los principios democráticos. Gobernar la globalización. N¹52-1997.

9) El N 153 - enero-febrero de 1998 contiene artículos referidos a pueblos indígenas y democracia, pero no hay ningún artículo referido a Chile específicamente.

\section{Corporación de Promoción Universitaria. C.P.U/ Revista de Estudios Sociales}

1) Políticas públicas y necesidades de justicia de los sectores pobres. Mirtha Ulloa G. y Macarena Vargas. No $83-1995$.

2) Modernización. Claudio Rafael Vásquez. № 83 - 1995.

3) La modernización del Estado: una mirada desde las regiones. Sergio Boiser. № 85 - 1995.

4) Descentralización y gobierno local: logros y agenda futura. Nelson Amaro Nº 86 - 1995.

5) Reflexiones sobre la descentralización fiscal en Chile. Jaime Gatica. № 86 - 1995.

6) La participación local: realidad y desafío. Erika Carmona y Nancy Masbernat. N 88-1996.

7) Privatización y regionalización en Chile. № 89 - 1996.

8) La salud en Chile ¿más estado o más mercado? María Eliana Labra. № 89 - 1996.

9 ) Identidad Nacional Chilena: cogniciones, valoraciones y emociones. № 90 - 1996. 
10) Estado, participación y políticas públicas en las nuevas democracias de América Latina. Alfredo Rehren N 90 - 1996.

También existe en la biblioteca un documento hecho por C.P.U, CINDE, FLACSO e ICP-UC en 1991 que se llama "Desafíos del Estado en los años '90".

11) Gestión participativa local: posibilidades y limitaciones. Erika Carmona y Nancy Masbernat. N॰91 - 1997.

12) Integración regional y estructuras jurídicas. Raimundo Barros Charlín. Nº 92 - 1997.

13) Las demandas de la sociedad humana del tercer milenio. Sección Crítica. № 93 - 1997.

14) Del estado modernizador a la modernización del estado: el caso chileno. Darío Rodríguez, Luz Eugenia Cereceda, Guillermo Wormald y Danae de los Ríos. № 94 - 1997.

15) Acerca de los costos sociales de la modernización (desintegración social, atomia/anomia y desarrollo social) J ohan Galtong. № 93 - 1997.

16) Participación ciudadana en gobiernos locales chilenos: una propuesta alternativa. Francisco Fernández. № 94 - 1997.

17) Una idea de la globalización. Agustín Squella. Sección Crítica. № 94 - 1997.

18) Restricciones y potencialidades en el proceso de democratización. La democracia local en Chile. Nancy Masbernat. № 96 - 1998.

19) Mediación y pobreza. Un camino para re-mediar la pobreza. Clara Salgado Menchaca. № 96 1998.

7. Universidad Diego Portales. Facultad de Derecho. Centro de Investigaciones Jurídicas. Cuadernos de análisis jurídicos:

Actualmente desarrollan proyectos de investigación relativos a la familia y la modernización, y al tema de la Reforma Procesal Penal vista como política pública y demanda hacia el estado.

1) Criterios Orientadores de una moderna política penitenciaria. J uan Enrique Vargas. $N^{\circ} 21$ 1992.

2) Poder Judicial y sistema Político: las políticas de modernización. Carlos Peña G. № 22 1992.

3) ¿A qué nos obliga la democracia? Notas para el debate sobre la reforma judicial. Carlos Peña G. N²2 - 1992.

4) Sistema penal y medidas alternativas. M Angélica J iménez. N 24 - 1993.

5) Chile: Obstáculos y desafíos para los derechos humanos. Cecilia Medina. N 25 - 1993.

\section{Universidad ARCIS}

En relación al tema, tiene los siguientes documentos de trabajo.

1) Transición a la democracia y organizaciones populares. Tesis de sociología.

2) Los procesos de constitución y desarrollo de las organizaciones juveniles poblacionales en la transición a la democracia. Tesis. 
3) Construcción de Estado en Chile; historia reversa de la legitimidad. Gabriel Salazar, 1994.

4) Fuerzas globales, expresiones locales. Diplomado en gestión sustentable. Alfredo Rodríguez.

5) Hacia una nueva era política: estudios sobre las democratizaciones. Diplomado en gestión sustentable. Manuel Antonio Garretón.

6) Tesis sobre relaciones Internacionales: Tiempos de transición: una historia abierta.

7) Política y modernidad en Chile: discursos y postdictadura. Tesis.

8) Las comunicaciones y el cambio cultural: un análisis de caso en el contexto de la modernización del Estado. Tesis.

9) Seguridad ciudadana: del consenso político al control social del delito. Centro de investigaciones sociales, perspectivas críticas en Teoría política. Documento de trabajo № 26.

10) Chile hacia el 2000: desafíos y opciones. Nueva Sociedad, 1988.

11) La pobreza en Chile: un desafío de equidad e integración social. Despertar, 1996. Consejo Nacional de Superación de la Pobreza.

12) Sectores populares entre los claroscuros de la integración y la humanización. Valparaíso, editorial Cidpa, 1998.

13) Modernización versus democratización. Cecilia Montero. Ediciones Sur, 1990.

14) Desarrollo humano en Chile-1998: las paradojas de la modernización. Informe PNUD.

9. RENIB. Programa computacional de revistas. Biblioteca Derecho P.U.C.Ch:

1) Estado, gobernabilidad y desarrollo. Luciano Tomassini. Revista ciencia política. Vol. $14 \mathrm{~N}^{\circ} 1$ - 2. 1994.

2) Una Tesis para la reforma del Estado en Chile. José Luis Cea. R. Ch. de Derecho. Vol. 19 N$^{\circ}$ 21992.

3) Conferencia del ex presidente de la República, don Patricio Aylwin A. sobre proceso de modernización del Estado. Revista Chilena de administración pública, № 1 julio 1994.

4) La modernización del Estado: una estrategia de operacionalización. Eliana Castillo. Rev. Chilena de administración pública. 1995.

5) Reflexiones sobre democratización y democracia participativa. Revista persona y sociedad. ILADES. Vol. VIII, 1994.

6) Hacia el reemplazo de la forma jurídica del Estado: la unitaria por la regional. Hernán Molina. Revista de Derecho Universidad de Concepción, 1992.

7) Tenemos la transición más imperfecta del Conosur. Tomás Moulian. La Nación. 27 de julio de 1997.

10. Universidad de Chile, Instituto de Ciencia Política

\section{Serie Material de Discusión:}

Material de Discusión N 17: "Desafíos para el Estado y la sociedad chilena en el contexto de la modernización" Luis Hernán Ramírez. Diciembre de 1997. 